\title{
Cactaceae na Serra Negra, Minas Gerais, Brasil ${ }^{1}$
}

\author{
Cactaceae in the Serra Negra, Minas Gerais, Brazil
}

Diego Rafael Gonzaga ${ }^{2,6}$, Daniela Zappi ${ }^{3}$, Samyra Gomes Furtado ${ }^{4}$ \& Luiz Menini Neto ${ }^{5}$

\begin{abstract}
Resumo
Apresenta-se o estudo taxonômico de Cactaceae na Serra Negra, Minas Gerais. A família está representada na área por cinco gêneros e nove espécies, listados a seguir: Arthrocereus melanurus subsp. magnus, Hatiora salicornioides, Lepismium houlletianum, Opuntia monacantha, Rhipsalis elliptica, R. floccosa subsp. pulvinigera, $R$.juengeri, $R$. lindbergiana e $R$. pilocarpa, sendo a primeira e a última consideradas ameaçadas de extinção na flora de Minas Gerais. Ainda deve ser destacado o fato de que Arthrocereus melanurus subsp. magnus teve o conhecimento de sua área de distribuição ampliada, pois era considerada endêmica do Parque Estadual do Ibitipoca. Os dados apresentados demonstram que a conservação de áreas como a Serra Negra, uma área atualmente não protegida, é de suma importância. Esta região vem sofrendo distúrbios devido a frequente visitação desorganizada, acompanhada de coleta ilegal de plantas, assim como transformação de remanescentes florestais e áreas de campo em áreas de pastagem aumentando o status de ameaça que já atinge algumas das espécies ali encontradas. São apresentadas chave de identificação, descrições, ilustrações, comentários taxonômicos e ecológicos para as espécies.
\end{abstract}

Palavras-chave: conservação, Floresta Atlântica, florística, Serra da Mantiqueira, taxonomia.

\begin{abstract}
The taxonomic study of Cactaceae in Serra Negra, Minas Gerais is presented. The family is represented in the area by five genera and nine species: Arthrocereus melanurus subsp. magnus, Hatiora salicornioides, Lepismium houlletianum, Opuntia monacantha, Rhipsalis elliptica, R. floccosa subsp. pulvinigera, R.juengeri, $R$. lindbergiana and $R$. pilocarpa. The first and last species are considered threatened for the State of Minas Gerais. It must be highlighted that Arthrocereus melanurus subsp. magnus was known previously only from the Parque Estadual do Ibitipoca and the present data resulted on an expansion of its known distribution area. Conservation of not yet protected areas like Serra Negra is very important, because their unique assemblage of species is constantly damaged by frequent and disorganized tourism and illegal plant collection. Local forest and natural fields are being further degraded as they are transformed into pasture land, and the threats faced by many species continue to grow. Identification keys, descriptions, illustrations, taxonomic and ecologic comments are provided for the species treated.
\end{abstract}

Key words: conservation, Atlantic Forest, floristics, Mantiqueira Range, taxonomy.

\section{Introdução}

Cactaceae Juss. compreende 127 gêneros e cerca de 1438 espécies distribuídas quase que exclusivamente na América tropical e subtropical, desde o Canadá até a Patagônia. Apenas Rhipsalis baccifera (J.M. Muell.) Stearn ocorre também no Paletrópico (Hunt et al. 2006). Os principais centros de diversidade e endemismo da família estão localizados no México e sudoeste dos Estados Unidos, na região central da cordilheira dos Andes, especialmente no Peru e na Bolívia e na região leste do Brasil, onde as Cactaceae ocorrem em diversos tipos de habitat (Taylor \& Zappi 2004).

\footnotetext{
${ }^{1}$ Parte do trabalho de conclusão de curso do primeiro autor.

${ }^{2}$ Centro de Ensino Superior de Juiz de Fora, Curso de Ciências Biológicas, Campus Arnaldo Janssen, Luz Interior 345, Santa Luzia, 36030-776, Juiz de Fora, MG, Brasil.

${ }^{3}$ Gardens by the Bay, Singapore/Royal Botanic Gardens, Kew, UK

${ }^{4}$ Universidade Federal de Juiz de Fora, Inst. Ciências Biológicas, Martelos, 36036-330 Juiz de Fora, MG, Brasil.

${ }^{5}$ Centro de Ensino Superior de Juiz de Fora, Campus Arnaldo Janssen, Luz Interior 345, Santa Luzia, 36030-776, Juiz de Fora, MG, Brasil.

${ }^{6}$ Autor para correspondência: diego.gonzaga@gmail.com
} 
No Brasil ocorrem cerca de 330 espécies distribuídas pelas Regiões Nordeste (90), Sudeste (120), Centro-Oeste (33), Sul (70) e Norte (17). Destas, 182 são endêmicas do país, com o maior nível de endemismo concentrado na região Sudeste (com cerca de 100 espécies). Em relação ao número de gêneros, 37 são endêmicos do Brasil (Silva et al. 2011).

A região da Serra Negra, no sudeste de Minas Gerais, vem sendo estudada de forma sistemática desde 2003 (Salimena et al. 2013). Em virtude de dados preliminares provenientes deste estudo, foi constatada a alta diversidade de espécies no local, sendo recomendada a investigação científica em forma de inventários para aumentar a base de conhecimento da região (Drummond et al. 2005). Vários estudos realizados reforçam a importância florística da região (Menini Neto et al. 2009; Abreu et al. 2011; Feliciano \& Salimena 2011; Matozinhos \& Konno 2011; Valente et al. 2011; Blaser et al. 2012; Dutra et al. 2012; Souza et al. 2012; Mezzonato-Pires et al. 2013; Salimena et al. 2013). No entanto, a despeito da importância biológica reconhecida, existem apenas duas unidades de conservação, as Reservas Particulares do Patrimônio Natural no município de Rio Preto (RPPN São Lourenço do Funil) e no município de Lima Duarte (RPPN Serra Negra) (Menini Neto et al. 2009), de modo que a maior parte da região encontra-se desprotegida, sofrendo com o turismo desordenado, coleta ilegal de plantas e utilização de suas áreas campestres como pastagens (obs. pessoal).

O objetivo deste estudo é apresentar o tratamento taxonômico de Cactaceae para a Serra Negra, contribuindo com o conhecimento florístico da região, bem como do estado de Minas Gerais. São apresentadas chave de identificação, descrições, ilustrações, comentários taxonômicos e ecológicos para as espécies.

\section{Material e Métodos}

A Serra Negra está localizada entre os municípios de Rio Preto, Lima Duarte, Olaria e Santa Bárbara do Monte Verde (22 $05^{\circ}$ 'S e $\left.43^{\circ} 49^{\prime} \mathrm{W}\right)$ (Fig. 1), apresentando uma área aproximada de 10.000 ha, composta de relevo acidentado, com altitude máxima de $1.698 \mathrm{~m}$. O clima é do tipo Cwb (segundo Köppen), mesotérmico úmido, com invernos secos e frios e verões brandos e úmidos. A média da precipitação anual é de $1.886 \mathrm{~mm}$ (Menini Neto et al. 2009; Valente et al. 2011; Souza et al. 2012; Salimena et al. 2013).

A vegetação da Serra Negra é caracterizada por um mosaico composto por campos rupestres e formações florestais, como floresta ombrófila densa montana e altomontana e floresta estacional semidecidual montana (Menini Neto et al. 2009; Valente et al. 2011; Salimena et al. 2013).

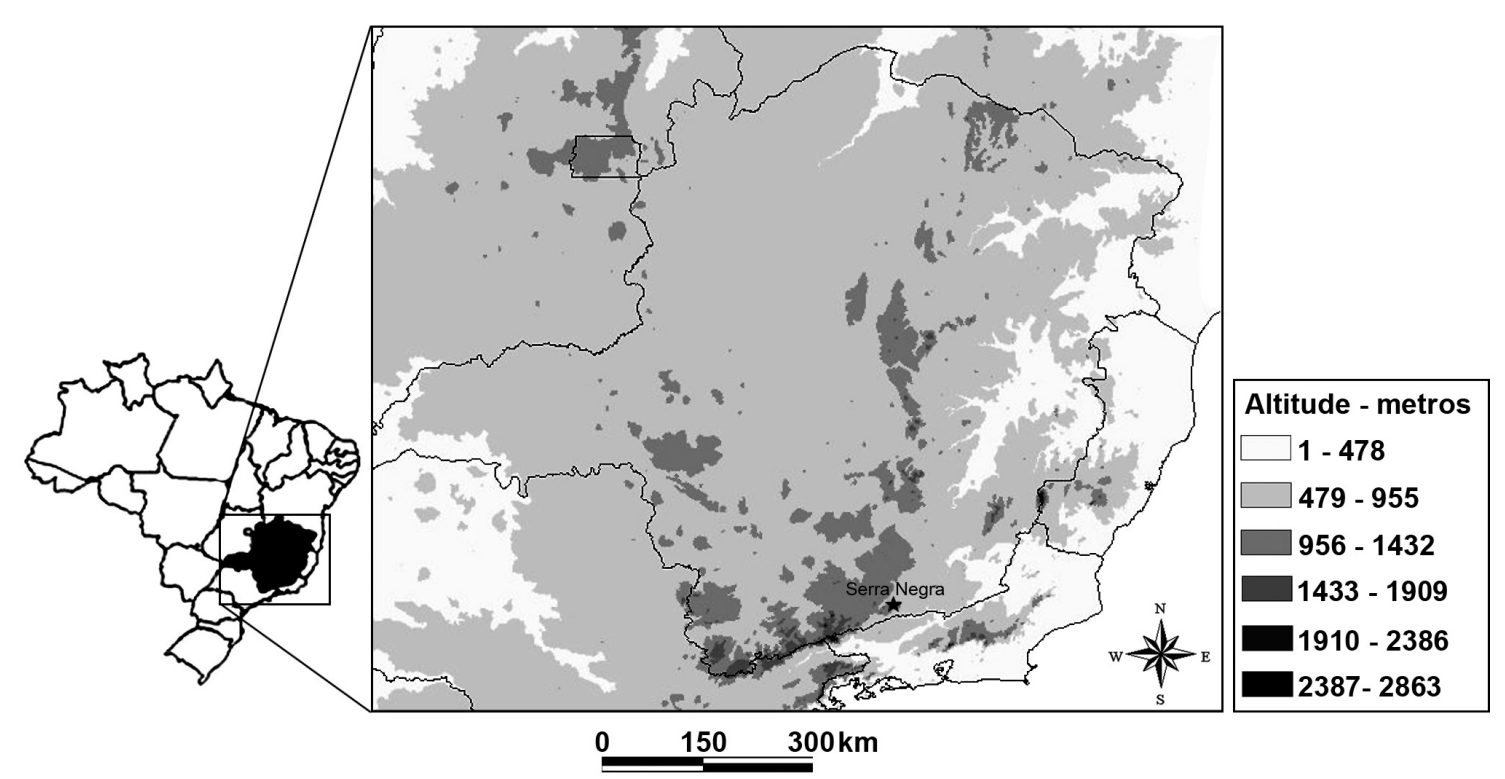

Figura 1 - Localização da área de estudo. Fonte: Salimena et al. (2013).

Figure 1 - Location of the studied area. Source: Salimena et al. (2013). 
A maioria do material utilizado é proveniente de coletas do projeto da Flora da Serra Negra desenvolvido pela Universidade Federal de Juiz de Fora entre 2003 e 2010 e complementado por coletas específicas para o presente estudo, feitas entre abril e dezembro de 2012. Os dados relevantes foram anotados em campo e as plantas foram fotografadas e publicadas em formato de guia de campo (Rapid Color Guide) pelo "The Field Museum of Chicago" (disponível em: http://fm2.fieldmuseum.org/plantguides/guide pdfs/463\%20Cactaceae $\% 20$ Serra $\% 20$ Negra.pdf). As plantas foram coletadas e herborizadas segundo a metodologia usual (Fidalgo \& Bononi 1989). Os exemplares encontram-se depositados no herbário CESJ (acrônimo segundo Thiers continously updated).

As descrições são baseadas em material herborizado e de flores e frutos acondicionados em via úmida coletados na Serra Negra e, quando necessário, em material adicional proveniente de outras localidades. No caso de Rhipsalis elliptica dados da morfologia floral foram obtidos a partir de Calvente (2010). A descrição da família foi baseada em Souza \& Lorenzi (2012).

\section{Resultados e Discussão}

Foram registradas nove espécies distribuídas em cinco gêneros na área estudada: Arthrocereus melanurus subsp. magnus, Hatiora salicornioides, Lepismium houlletianum, Opuntia monacantha, Rhipsalis elliptica, R. floccosa subsp. pulvinigera, $R$. juengeri, $R$. lindbergiana e $R$. pilocarpa. Epiphyllum phyllanthus (L.) Haw. foi observada apenas estéril, de modo que não foi coletada e incluída no tratamento taxonômico. A representatividade de Rhipsalis na Serra Negra reflete o fato de este ser o gênero mais rico em espécies dentre as Cactaceae no Brasil (Calvente 2010; Zappi et al. 2013), juntamente por tratarse principalmente de um gênero composto por espécies epífitas, forma de vida que se destaca na flora da região, devido à presença das florestas de grota e, sobretudo, nebulares nas cotas altimétricas mais elevadas (Menini Neto et al. 2009; Salimena et al. 2013). Ocorre ainda uma espécie arenícola e/ ou rupícola (A. melanurus subsp. magnus) e uma espécie terrícola (O. monacantha).

Dentre as Cactaceae registradas na Serra Negra merece destaque A. melanurus subsp. magnus, considerada endêmica do Parque Estadual do Ibitipoca (Taylor \& Zappi 1997) mas que foi, durante o presente estudo, registrada em diferentes pontos da Serra Negra, associadas aos afloramentos quartzíticos nos campos rupestres. Além desta, apenas três outras espécies são compartilhadas com a flora do Parque $(H$. salicornioides, $R$. floccosa subsp. floccosa, $R$. juengeri) (Gonzaga et al. 2014), a despeito da pequena distância entre as áreas (ca. $25 \mathrm{~km}$ ) e da semelhança entre o tipo de vegetação.

Para a Região Sudeste do Brasil há estudos sobre Cactaceae realizados nos estados de Minas Gerais, Rio de Janeiro e São Paulo, dos quais pode ser destacado o estudo mais amplo realizado por Taylor \& Zappi (2004), que trataram da flora de Cactaceae do Leste do Brasil, incluindo o estado de Minas Gerais em sua totalidade além da região norte do Rio de Janeiro. Dois outros estudos amplos, relacionados à flora de Cactaceae em dois estados são o de Calvente et al. (2005) que fizeram um levantamento das Cactaceae no Rio de Janeiro e Zappi et al. (2007) que apresentaram o tratamento na Flora de São Paulo. Devido à dificuldade de coleta, muitas vezes as Cactaceae são pouco representadas nos herbários (Calvente 2010), e tratamentos florísticos pontuais continuam a incrementar o conhecimento da família na Região Sudeste do Brasil (e.g. Zappi 1989; Zappi 1990; Taylor \& Zappi 1991; Zappi \& Taylor 2003, em Minas Gerais; Rizzini et al. 1990; Freitas 1992; Arbo-Gallas \& Verçoza 2012, no Rio de Janeiro; Lombardi 1991; 1995; Mendes \& Sebastiani 2012, para São Paulo).

Dentre as espécies registradas neste estudo, são citadas como ameaçadas de extinção no Brasil, Arthrocereus melanurus subsp. magnus no status Quase Ameaçada (NT) e Rhipsalis pilocarpa no status de Vulnerável (VU) (Silva et al. 2011). A última é citada também pela IUCN (2013) na mesma categoria de ameaça. Para Minas Gerais são listados Arthrocereus melanurus subsp. magnus no status Criticamente em Perigo (CR) e Rhipsalis pilocarpa no status Em Perigo (EN) (Biodiversitas 2007).

\section{Tratamento taxonômico}

Cactaceae Juss.

Plantas arbóreas, arbustivas, subarbustivas a herbáceas, rupícolas, terrícolas ou epífitas, geralmente suculentas e com caule fotossintetizante, às vezes segmentado, ramos frequentemente achatados ou colunares e costelados, ou globosos. Ramos curtos do tipo braquiblasto transformados 
em aréolas, originando folhas (em Pereskia Mill.), folhas escamiformes, espinhos de morfologia variada, e também outros ramos tanto vegetativos como reprodutivos. Folhas, quando presentes (como em Pereskia Mill.) alternas, simples, sem estípulas, geralmente carnosas. Inflorescência cimosa, frequentemente reduzida a uma única flor; flores geralmente vistosas, bissexuadas, actinomorfas ou ligeiramente zigomorfas; segmentos do perianto numerosos e espiralados; estames numerosos, anteras rimosas, disco e/ou câmara nectarífera frequentemente presentes; ovário geralmente ínfero (raramente súpero em Pereskia), e então envolvido por um hipanto receptacular imerso no ramo vegetativo, 3-pluricarpelar, unilocular; placentação parietal, pluriovulado, estilete geralmente alongado, com estigma ramificado. Fruto baga ou cápsula carnosa (Souza \& Lorenzi 2012).

\section{Chave para identificação das espécies de Cactaceae na Serra Negra}

1. Ramos espinescentes, espinhos pungentes, plantas rupícolas ou terrícolas.

2. Cladódios costelados, flores alvas, frutos esféricos .... 1. Arthrocereus melanurus subsp. magnus

2’. Cladódios aplanados, flores amarelas, frutos clavados

4. Opuntia monacantha

1'. Ramos inermes ou aréolas com cerdas finas, flexíveis, plantas geralmente epífitas.

3. Ramos clavados, flores amarelas a alaranjadas

2. Hatiora salicornioides

3'. Ramos aplanados ou cilíndricos, flores alvas ou róseas.

4. Ramos aplanados.

5. Ramos de crescimento indeterminado, não articulados na porção apical, ramificação a partir da base, crenas agudas 3. Lepismium houlletianum

5'. Ramos articulados de crescimento determinado, ramificação a partir do ápice, crenas arredondadas 5.1. Rhipsalis elliptica

4'. Ramos cilíndricos.

6. Aréolas cerdosas.

7. Ramos, hipanto e frutos glabros 5.2. Rhipsalis floccosa subsp. pulvinigera

7'. Ramos, hipanto e frutos pilosos 5.5. Rhipsalis pilocarpa

6'. Aréolas glabras.

8. Flores alvas, 1,2-1,5 cm diâm., dispostas apenas nos ápices dos ramos, com mais de 60 estames, frutos róseos a avermelhados 5.3. Rhipsalis juengeri

8'. Flores creme, 0,5-0,6 cm diâm., dispostas ao longo dos ramos, com menos de 50 estames, frutos alvos translúcidos a leitosos 5.4. Rhipsalis lindbergiana

1. Arthrocereus melanurus subsp. magnus N.P.Taylor \& Zappi, Cact. Consensus Initiat. 3: 7. 1997.

Fig. 2a-b

Arbusto ramificado; arenícola ou rupícola em campo rupestre, até 1,5-2 m alt.; cladódios costelados verde-claros, ca. 4,2 cm diâm., ramificados apenas na base (acima da base somente quando cortados), ca. 20 costelas, ca. 3 $\times 2 \mathrm{~mm}$, aréolas ca. $4 \mathrm{~mm}$ larg., distanciadas 6-8 $\mathrm{mm}$ entre si, espinhos $60-70$ por aréola, centrais $1,5-3 \mathrm{~cm}$ compr., radiais $2-5 \mathrm{~mm}$ compr. Botão floral verde hirsuto; flores alvas, ca. $4 \times 5 \mathrm{~cm}$, de antese noturna; ca. 62 segmentos do perianto, segmentos externos do perianto lanceolados, ca. $1,8 \times 0,5 \mathrm{~cm}$, esverdeados, segmentos internos do perianto lanceolados, ca. $4 \times 1 \mathrm{~cm}$; tubo floral ca. $7 \mathrm{~cm}$ compr., dotado de tricomas castanhos; ca. 230 estames, estames do raio ca. $2,5 \mathrm{~cm}$ compr., estames centrais ca. 4,5 cm compr.; estilete ca. 9,5 cm compr., estigma ca. $7 \mathrm{~mm}$ compr., 16-lobado, lobos ca. $5 \mathrm{~mm}$ compr.; frutos globosos, verde passando a verde-acastanhado, indeiscente, ca. 3 $\mathrm{cm}$ diâm., dotado de tricomas; sementes negras, cocleariformes, ca. $1 \mathrm{~mm}$ compr.; testa verrucosa. Material examinado: Rio Preto, 25.IV.2005, fr., C.N. Matozinhos et al. 188 (CESJ); Rio Preto, 8.XII.2007, fl., F.S. Souza et al. 322 (CESJ); Lima Duarte, 5.IV.2009, fr., J.H.C. Ribeiro et al. 85 (CESJ); Lima Duarte, 8.XII.2012, fl., D.R. Gonzaga et al. 117 (CESJ).

Arthrocereus melanurus subsp. magnus é endêmica de Minas Gerais, ocorrendo principalmente com hábito arenícola e/ou rupícola em campo rupestre. Diferencia-se das demais subespécies de $A$. melanurus pelo maior tamanho e diâmetro dos cladódios (maior que 1,5 m alt., ultrapassando $2 \mathrm{~m}$ com freqüência, enquanto nas 

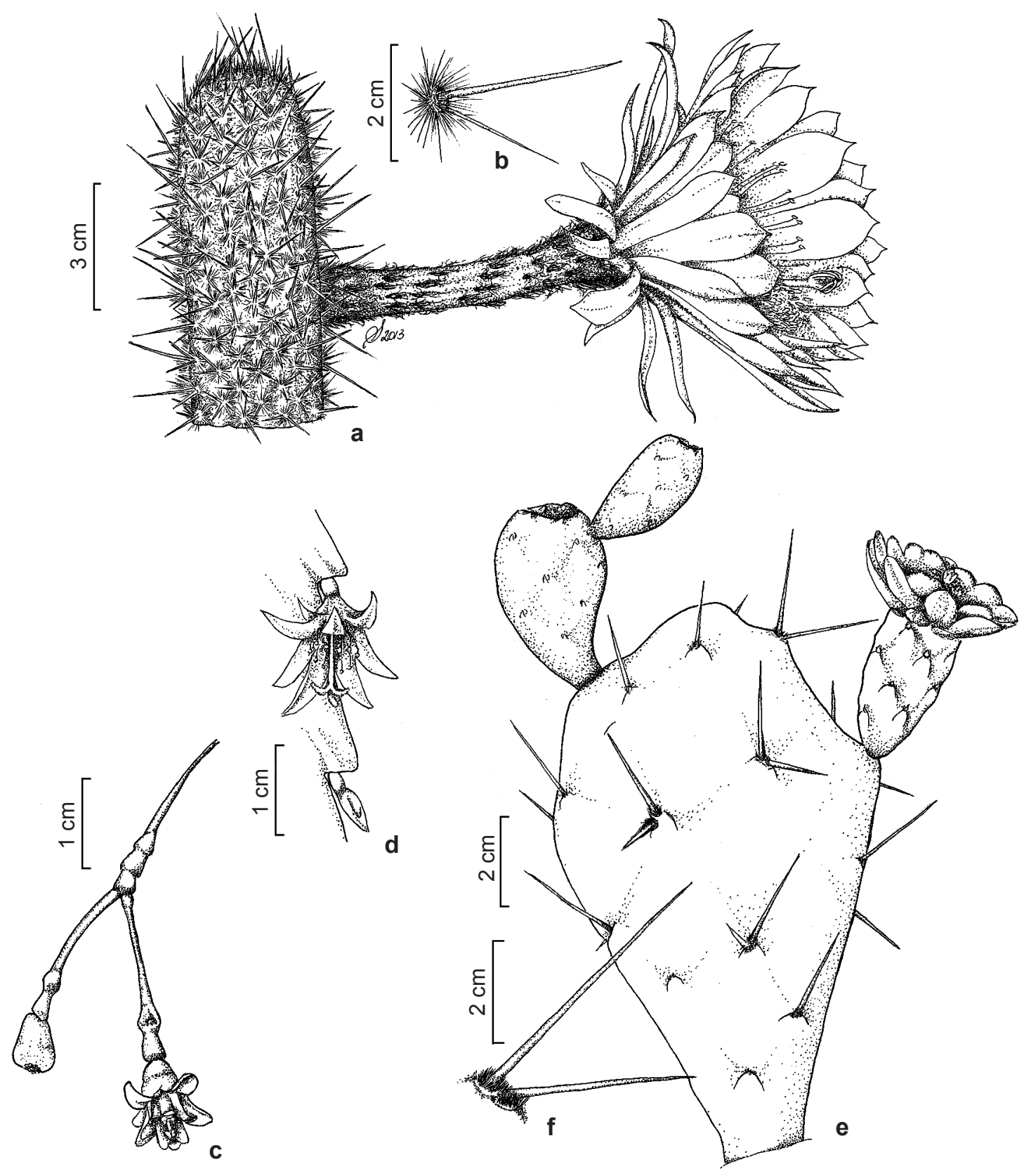

Figura 2 - a-b. Arthrocereus melanurus subsp. magnus - a. ápice do ramo e flor; b. aréola. c. Hatiora salicornioides - ápice do ramo com flor e fruto. d. Lepismium houlletianum - fragmento de ramo com flor e botão. e-f. Opuntia monacantha - e. ramo com flor e frutos; f. detalhe da aréola. (a-b Gonzaga 117; c Gonzaga 33, 29; d Salimena 3482; e-f Gonzaga 121).

Figure 2 - a-b. Arthrocereus melanurus subsp. magnus - a. apex of branch and flower; b. detail of areole. c. Hatiora salicornioides apex of branch with flower and fruit. d. Lepismium houlletianum - fragment of branch with flower and bud. e-f. Opuntia monacantha - e. branch with flower and fruits; f. detail of areole. (a-b Gonzaga 117; c Gonzaga 33, 29; d Salimena 3482; e-f Gonzaga 121). 
outras duas subespécies possui entre 0,8 e $1 \mathrm{~m}$ alt.). Esta subespécie é endêmica de Minas Gerais e era conhecida apenas no Parque Estadual do Ibitipoca (Taylor \& Zappi 1997), distante ca. 25 km da Serra Negra. Foi registrada na Serra Negra e apresenta populações pequenas (com média de 10 indivíduos) e esparsas em pontos isolados, principalmente em afloramentos rochosos da Gruta do Funil (a ca. 900 m.s.m.), trilha para o Ninho da Égua (a ca. 1200 m.s.m.) e da Cachoeira da Água Amarela (a ca. 1000 m.s.m.). É considerada uma espécie Quase Ameaçada (Silva et al. 2011) de acordo com os critérios da IUCN e Criticamente em Perigo segundo a Lista de Espécies Ameaçadas da Flora de Minas Gerais (Biodiversitas 2007).

2. Hatiora salicornioides (Haw.) Britton \& Rose, Stand. Cycl. Hort. 3: 1433. $1915 . \quad$ Fig. 2c Epífita ou rupícola; ramos basais lenhosos, 4-5 mm larg.; ramos terminais verde-escuros, verde-claros a avermelhados, ca. $1 \mathrm{~mm}$ larg., segmentos fortemente clavados a cilíndricos ca. $3 \mathrm{~mm}$ larg.; 2-5 furcados; entrenós 1,5-2,7 cm compr.; aréolas terminais, tricomas alvos. Botão floral creme-esverdeado; flores amareloalaranjado, ca. $11 \times 8 \mathrm{~mm}$; uma flor por aréola; semi-tubulares, ca. 20 segmentos do perianto; segmentos externos 2-4 × $2 \mathrm{~mm}$, ovados, segmentos internos 6-9 × $4 \mathrm{~mm}$, lanceolados; ca. 63 estames; filete ca. $4 \mathrm{~mm}$ compr.; estilete ca. $6 \mathrm{~mm}$ compr., estigma 3-lobado, lobo ca. $1 \mathrm{~mm}$ compr.; frutos obovóides a turbinados, 5-6 × 5-7 $\mathrm{mm}$, alvos; sementes castanhas ca. $1 \mathrm{~mm}$ compr.; reniformes, testa levemente sulcada.

Material examinado: Rio Preto, 9.XI.2005, fl., C.N. Matozinhos et al. 260 (CESJ); Rio Preto, 13.X.2007, fr., F.S. Souza et al. 284 (CESJ); Lima Duarte, 15.XI.2008, fr. F.R.G. Salimena \& P.H. Nobre 2744 (CESJ); Rio Preto, 2.IX.2012, fr., D.R. Gonzaga et al. 29 (CESJ); Rio Preto, 29.IX.2012, fl., D.R. Gonzaga et al. 33 (CESJ).

Hatiora salicornioides é endêmica do Brasil, ocorrendo como epífita ou rupícola na Bahia, Minas Gerais, Espírito Santo, São Paulo, Rio de Janeiro e Paraná (Zappi et al. 2013). Apresenta segmentos terminais clavados que a diferencia das demais espécies do gênero no Brasil. Na Serra Negra é uma espécie incomum e foi encontrada como epifítica no interior de fragmento de floresta ombrófila densa aluvial, conhecida localmente como Mata do Cambuí (ca. 900 m.s.m.) e nas florestas nebulares do Ninho da Égua (ca. 1400 m.s.m.) e observada como rupícola na Trilha da Antena.
3. Lepismium houlletianum (Lem.) Barthlott, Bradleya 5: 99. $1987 . \quad$ Fig. 2d

Epífita facultativa; ramos terminais aplanados e pendentes, verdes, com camada cerosa na superfície, crenas agudas, 11-33 × 1,8-3,5 cm; aréolas laterais não imersas, distanciadas, ca. 1,2 $\times 2,2 \mathrm{~cm}$. Flores alvas desenvolvendo-se na lateral dos ramos, 1 flor por aréola, 1,1-1,7 × 0,7-1,5 cm; pericarpelo ca. $4 \times 3 \mathrm{~mm}$; 6-12 segmentos do perianto, fundidos na base, segmentos externos 3-8 $\times$ 3-4 mm triangulares, segmentos internos do perianto $12-16 \times 3 \mathrm{~mm}$, lanceolados, estames 22-35, filetes 4-10 mm compr.; estilete 7-9 mm compr., estigma 3-lobado, lobo 2-3 mm; frutos oblongos, 7-8 × $6 \mathrm{~mm}$, magenta, lisos, nítidas quando maduros, inseridos em aréolas; sementes ca. $2 \mathrm{~mm}$ compr., elipsóides a reniformes, testa rugosa, castanho-escuro, negra a avermelhada . Material examinado: Rio Preto, 3.X.1987, fr., F.R.G. Salimena et al. (CESJ 21620); Rio Preto, 10.XI.2005, fr., K. Antunes 210 (CESJ); Lima Duarte, 14.X.2008, fr., C.N. Matozinhos \& N.L. Abreu 423 (CESJ); Rio Preto, 11.VIII.2012, fr., D.R. Gonzaga et al. 5 (CESJ); Lima Duarte/Olaria, 8.VI.2012, fl., F.R.G. Salimena et al. 3482 (CESJ).

Lepismium houlletianum está distribuída pela Argentina, Brasil e Paraguai. No Brasil ocorre em Minas Gerais, São Paulo, Rio de Janeiro, Paraná e Santa Catarina (Zappi et al. 2013). Pode ser diferenciada de $R$. elliptica por apresentar ramificação a partir da base dos ramos não segmentados, crenas agudas e frutos de coloração róseo-escuro, enquanto que $R$. elliptica possui ramos articulados com crescimento apical, crenas arredondadas e frutos magenta. Na Serra Negra pode ser encontrada principalmente como rupícola em afloramentos rochosos ou epífita em um fragmento de floresta de grota, no Cânion do Funil (a ca. 900 m.s.m.).

4. Opuntia monacantha Haw., Suppl. Succ.: 81 . 1819.

Fig. 2e-f

Sub-arbusto, 1-1,5m alt.; ramos verdenítidos, 13-20,5 × 7-9 cm, obovados de base estreita; espinhos 1-2 por aréola, alvos a castanhos distribuídos ao longo dos ramos, espinhos 2,3-5,2 cm compr. Botão floral vermelho; flores amarelas ca. 2,5 $\times 5 \mathrm{~cm}$, pericarpelo verde $4,4-5 \times 2-2,5 \mathrm{~cm}$, ca. 25 segmentos do perianto, segmentos externos do perianto ca. $1 \times 1,3 \mathrm{~cm}$ vináceos a vermelhos, obovados, segmentos internos do perianto ca. $3 \times 2 \mathrm{~cm}$ amarelos, obovados; ca. 310 estames, filete ca. $1 \mathrm{~cm}$ compr., estigma 5-7 lobado, lobo 
ca. $5 \mathrm{~mm}$ compr.; estilete creme ca. 1,7 $\times 0,4$ $\mathrm{cm}$, claviforme; frutos clavados, ca. $6 \times 3,5 \mathrm{~cm}$, frequentemente desenvolvendo-se sobre os mais antigos, verde quando imaturo passando a verdeavermelhado quando maduro, aréolas persistentes com gloquídeos numerosos; sementes reniformes ca. $3 \mathrm{~mm}$ compr.

Material examinado: Lima Duarte, 8.XII.2012, fl, fr., D.R. Gonzaga et al. 121 (CESJ).

Opuntia monacantha ocorre na Argentina, Brasil, Paraguai, Uruguai (Zappi et al. 2007). No Brasil a espécie está distribuída nos estados da Bahia, Sergipe, Espírito Santo, Minas Gerais, Rio de Janeiro, São Paulo, Paraná, Rio Grande do Sul e Santa Catarina (Zappi et al. 2013). Na Serra Negra se diferencia das demais espécies pelo hábito terrícola, cladódios aplanados e por apresentar forma arbustiva. Foi observada em dois pontos da trilha próximo a Cachoeira do Arco-íris (a ca. 1200 m.s.m.), com uma população numerosa.

5.1 Rhipsalis elliptica G. Lindb ex. K Schum. Fl. bras. 4(2): 293. 1890.

Fig. 3a

Epífita; ramos aplanados, verde nítidas, ramificações nas aréolas apicais e laterais, ramos elípticos a rômbicos, 7-13,5 × 2-4 cm, margem crenada, crenas arredondadas, aréolas 1,3-2,5 cm distantes entre si; flores alvas a róseas ca. $14 \times$ $11 \mathrm{~mm}$, laterais, inseridas nas aréolas, 1 flor por aréola, segmentos do perianto ca. 10, segmentos externos do perianto obovados ca. $5 \times 5 \mathrm{~mm}$, segmentos internos do perianto $14 \times 11 \mathrm{~mm}$, pericarpelo globoso, ca. $4 \times 4 \mathrm{~mm}$; estames ca. 60 , filetes 2-7 mm compr., estigma e estilete exsertos; estigma 5-lobado, ca. $4 \mathrm{~mm}$ compr., lobo ca. $2 \mathrm{~mm}$ compr., estilete ca. $4 \mathrm{~mm}$ compr.; frutos ovados, verde quando imaturos a róseo quando maduros, 6-8 × 4,5 mm, segmentos do perianto persistentes; sementes castanho-escuras, ca. $1 \mathrm{~mm}$ compr., elipsóides a reniformes, testa verrucosa.

Material examinado: Rio Preto, 10.XI.2005, fr.; $K$. Antunes et al. 200 (CESJ); Rio Preto, 11.VIII.2012, fr., D.R. Gonzaga et al. 6 (CESJ); Rio Preto, 1.IX.2012, fr., D.R. Gonzaga et al. 17 (CESJ); Rio Preto, 2.IX.2012, fr.; D.R. Gonzaga et al. 30 (CESJ).

Material adicional: BRASIL. MINAS GERAIS: Bom Jardim de Minas, 13.IV.1991, fl., M.C. Brügger et al. s.n. (CESJ 26277).

Rhipsalis elliptica é endêmica do Brasil, ocorrendo nas regiões Sudeste (exceto Espírito Santo) e Sul (Zappi et al. 2013). É facilmente diferenciada das demais espécies de ramos aplanados por apresentar frutos róseos translúcidos e das espécies de Rhipsalis da Serra Negra por ser a única de ramos aplanados. Na Serra Negra foi encontrada como epífita em floresta de grota no Cânion da Gruta do Funil (a ca. 900 m.s.m.) e em florestas nebulares do Ninho da Égua (a ca. 1400 m.s.m.).

5.2 Rhipsalis floccosa subsp. pulvinigera (G. Lindb.) Barthlott \& N.P. Taylor Bradleya 13: 55 1995.

Fig. 3b-c

Epífita; ramos cilíndricos, verde-escuros a verde-acinzentados, 3-5 mm diâm., ramos terminais 6-21 cm compr.; aréolas cerdosas ao longo dos ramos, cerdas alvas e numerosas. Botões florais vermelhos, na superfície dos ramos, surgindo no interior das aréolas cerdosas; flores terminais a subterminais, alvas a róseas, 1 flor por aréola, ca. $7 \times 10 \mathrm{~mm}$, pericarpelo triangular ca. $3 \times 5 \mathrm{~mm}$, segmentos do perianto ca. 13, segmentos externos triangulares a ovados $6 \times 3-4 \mathrm{~mm}$, segmentos internos lanceolados, 7-10 × 3-4 mm, estames 93 140, filete ca. $4 \mathrm{~mm}$ compr., estilete $4-5 \mathrm{~mm}$ compr., estigma ca. $2 \mathrm{~mm}$ compr., 4-5 lobado, lobo 1,5-2 mm compr.; frutos róseos, 5-8 $\times 7-8 \mathrm{~mm}$, globosos, levemente truncados no ápice, segmentos do perianto persistentes, inseridos em aréolas cerdosas; sementes castanho-escuras a avermelhadas, ca. $2 \times$ $1 \mathrm{~mm}$, reniformes, testa lisa, nítida.

Material examinado: Rio Preto, 10.IV.2007, fr., F.S. Souza et al. 258 (CESJ); Rio Preto, XI.2011, fl., R.J.V. Alves \& N.L. Abreu 8780 (CESJ); Rio Preto, 2.IX.2012, fl., D.R. Gonzaga et al. 27 (CESJ); Rio Preto, 2.IX.2012, fl., D.R. Gonzaga et al. 28 (CESJ).

Rhipsalis floccosa subsp. pulvinigera é endêmica do Brasil e ocorre em Pernambuco, Bahia e Sergipe, além dos estados das regiões Sudeste e Sul (Zappi et al. 2013). É bem caracterizada pela presença de aréolas cerdosas, nas quais se inserem botões, flores e frutos. O padrão cromático das flores é verde-claro ou branco-esverdeado (Taylor \& Zappi 2004), porém os exemplares da Serra Negra apresentam flores róseas. Na Serra Negra a espécie é encontrada frequentemente e com numerosos indivíduos nas florestas nebulares próximas à Cachoeira do Ninho da Égua (a ca. 1400 m.s.m.).

5.5 Rhipsalis juengeri Barthlott \& N.P.Taylor, Bradleya 13: 69. 1995.

Fig. 3d-e

Epífita; ramos cilíndricos delicados pendentes, verde-escuros, muito ramificados, ramos basais $2-3 \mathrm{~mm}$ larg., ramos terminais $2-3$ furcados, ca. $1 \mathrm{~mm}$ larg. 1,8-5,2 cm compr.; aréolas 


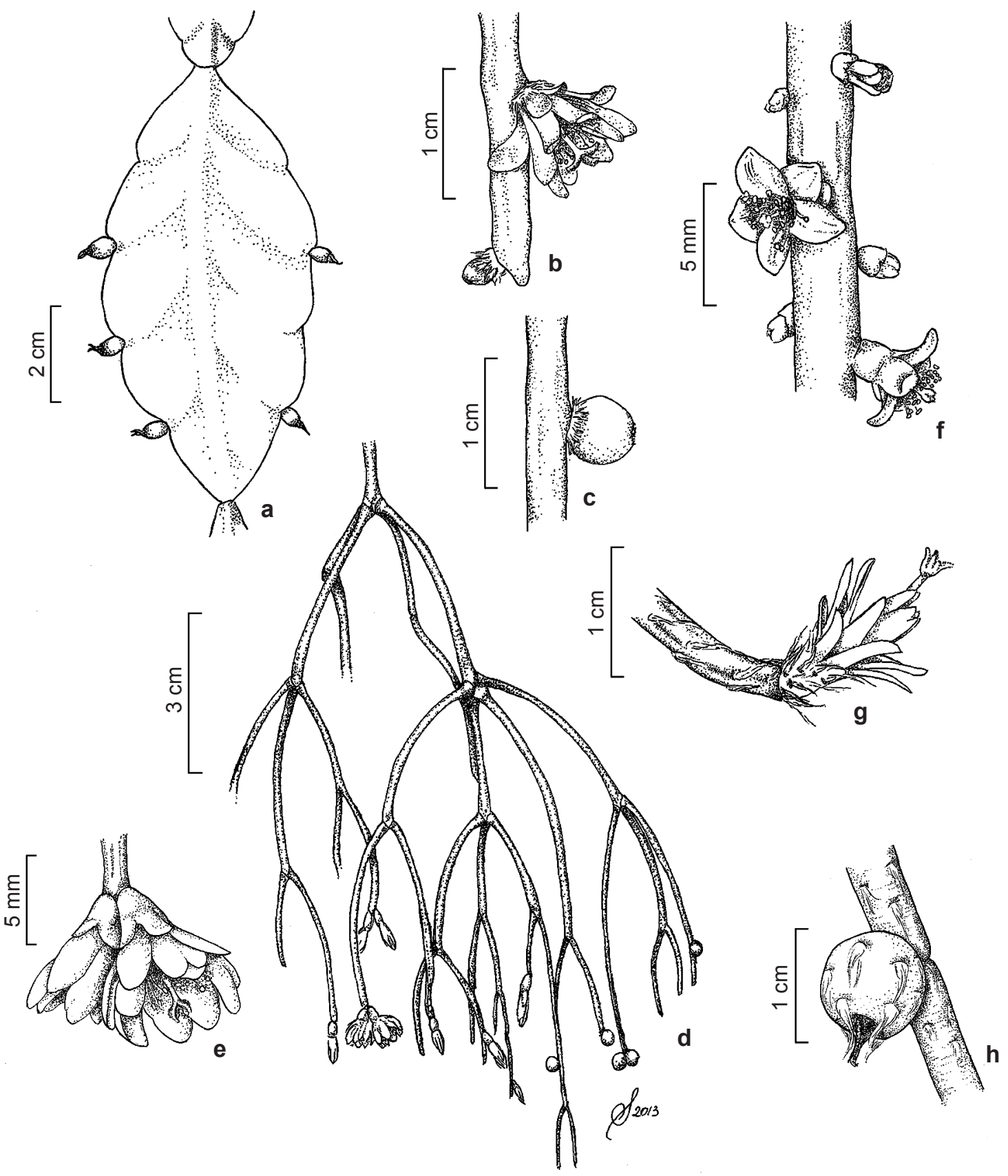

Figura 3 - a. Rhipsalis elliptica - fragmento de ramo com frutos. b-c. Rhipsalis floccosa subsp. pulvinigera - b. ápice de ramo com flor e botão; c. detalhe do fruto. d-e. Rhipsalis juengeri - d. vista geral da planta; e. ápice de ramo com flores. f. Rhipsalis lindbergiana - detalhe de ramo com flores e botões. g-h. Rhipsalis pilocarpa - g. ápice do ramo com flor; h. detalhe do fruto. (a Gonzaga 16; b-c Gonzaga 28, 27; d-e Gonzaga 47; f Gonzaga 18; g-h Gonzaga 34, 1). Figure 3 - a. Rhipsalis elliptica - fragment of branch with fruits. b-c. Rhipsalis floccosa - b. apex of branch with flower and bud; c. detail of fruit. d-e. Rhipsalis juengeri - d. general view of the plant; e. apex of branch with flowers. f. Rhipsalis lindbergiana - detail of branch with flowers and buds. g-h. Rhipsalis pilocarpa - g. apex of branch with flower; h. detail of fruit. (a Gonzaga 16; b-c Gonzaga 28, 27; d-e Gonzaga 47; f Gonzaga 18; g-h Gonzaga 34, 1). 
reduzidas no ápice dos ramos. Botão floral alvo; flores terminais a sub-terminais, ca. 8-10 × 3-4 $\mathrm{mm}$, campanuladas, alvas, pêndulas, inseridas em aréolas, 1-4 flores por aréola, pericarpelo ca. $2 \times$ $3 \mathrm{~mm}$., segmentos do perianto 10-14, segmentos externos do perianto ovados, 3-4 × $3 \mathrm{~mm}$, segmentos internos do perianto lanceolados, 6-10 $\times$ 2-3 mm, estames 35-43, estigma 3-5 lobado, lobo ca. $2 \mathrm{~mm}$ compr., filete $4-5 \mathrm{~mm}$ compr., estilete 6-7 $\times 1 \mathrm{~mm}$; frutos globoso-truncados, 5-6 × 5-6 mm, vermelhos, segmentos do perianto persistentes, 1-2 frutos por aréola; sementes reniformes a subreniformes, castanho-avermelhadas a negras, testa levemente rugosa a lisa, nítida, ca. $2 \times 1 \mathrm{~mm}$.

Material examinado: Rio Preto, 26.II.2006; fr.; P.L.Viana \& N.F.O. Mota 1996 (CESJ).

Material adicional: BRASIL. MINAS GERAIS: Lima Duarte, Parque Estadual do Ibitipoca. 2.XII.2003, fr., $L$. Menini Neto \& R.J.V. Alves 63 (CESJ); Lima Duarte, Parque Estadual do Ibitipoca, 28.X.2012, fl. e fr., D.R.Gonzaga et al. 50 (CESJ).

Rhipsalis juengeri é endêmica do Brasil, ocorrendo em Minas Gerais, Espírito Santo e São Paulo (Zappi et al. 2013). Pode ser diferenciada das demais espécies do gênero na Serra Negra por apresentar flores alvas pendentes terminais e frutos vermelhos truncados. Rhipsalis juengeri é muito confundida, em materiais herborizados, com $R$. campos-portoana Loefgr. devido aos frutos truncados. Porém esta espécie ocorre em São Paulo, Rio de Janeiro, Paraná, Santa Catarina e Rio Grande do Sul, não tendo registro para Minas Gerais (Zappi et al. 2013). Na Serra Negra é uma espécie rara, tendo sido observado apenas um indivíduo na região da floresta de grota do Cânion da Gruta do Funil, em altitude aproximada de 900 m.s.m.

5.3 Rhipsalis lindbergiana K.Schum. Fl. bras. 4(2): 271. 1890 .

Fig. $3 f$

Epífita; ramos cilíndricos pendentes de crescimento indeterminado, verde-escuros a verdeclaros, 1-3 mm larg., ramos basais 2-3 mm larg., ramos apicais 2,5-6 $\times 0,1 \mathrm{~cm}$; ramificações no ápice 2-4 furcadas, aréolas distribuídas ao longo dos ramos. Botões florais creme-acastanhados, na superfície dos ramos; flores alvacentas a cremes, 1 flor por aréola, desenvolvendo-se ao longo dos ramos e próximas do ápice, ca. $5 \times 6 \mathrm{~mm}$, pericarpelo ca. $2,5 \times 3 \mathrm{~mm}$, ovóide, esverdeado; segmentos do perianto 7-8, reflexos, segmentos externos do perianto triangulares $1,5-3 \times 2-3 \mathrm{~mm}$, segmentos internos do perianto lanceolados 4-5 $\times$ $2 \mathrm{~mm}$, ca. 44 estames amarelos a alvos, estigma 3-lobado, ca. 4 mm compr., lobos 0,5-1 mm compr.; estilete ca. $3 \mathrm{~mm}$ compr., filete 1,5-4 mm compr.; frutos globosos, ca. $6 \times 5 \mathrm{~mm}$, alvo-translúcido; sementes $0,6-1 \times 1 \mathrm{~mm}$, castanho-escuras, levemente achatadas lateralmente, testa verrucosa, ovóides a reniformes.

Material examinado: Rio Preto, 10.XI.2005, fr., $K$. Antunes 203 (CESJ); 18.III.2007, fr., L. Menini Neto et al. 365 (CESJ); 13.X.2007, fl., S.A. Roman et al. 28 (CESJ); 11.VIII.2012, fr., D.R. Gonzaga et al. 4 (CESJ); 11.VIII.2012, fl. e fr., D.R. Gonzaga et al. 7 (CESJ); 1.IX.2012, fl. e fl., D.R Gonzaga et al. 18 (CESJ).

Rhipsalis lindbergiana é endêmica do Brasil, ocorrendo em Pernambuco, Bahia e Sergipe, além dos estados da Região Sudeste (Zappi et al. 2013). Pode ser confundida com $R$. teres (Vell.) Steud. devido à forma dos frutos, porém se diferencia devido às flores menores e de segmentos do perianto triangulares. Nos estudos de Menini Neto et al. (2009) e Salimena et al. (2013) para a flora da Serra Negra a espécie está identificada como $R$. teres e $R$. baccifera, sendo corrigida no presente estudo. Espécie frequentemente encontrada na Serra Negra, principalmente na floresta estacional semidecidual da Fazenda Tiririca, floresta ombrófila densa aluvial da Mata do Cambuí, floresta de grota do Cânion da Gruta do Funil e Cachoeira da Água Amarela, entre 900 e 1000 m.s.m.

5.4 Rhipsalis pilocarpa Loefgr. Monatsschr. Kakteenk. 13: 52. 1903. Fig. 3g-h

Epífita ou rupícola; ramos cilíndricos pendentes, verde-escuros, ramificações no ápice, ramos basais 28-29,5 × 0,3-0,4 cm, ramos médios $8,5-27 \times 0,2-0,3 \mathrm{~cm}$, ramos apicais $2,5-7 \times 0,1-0,3$ $\mathrm{cm}$. Botão floral coberto por tricomas cremeacastanhos; flores terminais, campanuladas, 1-2 flores por aréola, 10-15 mm diâm., alvas, aréolas com tricomas numerosos, pericarpelo ca. $5 \times 4 \mathrm{~mm}$, obcônico, ca. 21 segmentos do perianto, segmentos externos triangulares a lanceolados ca. $8 \times 2 \mathrm{~mm}$, segmentos internos lanceolados ca. $10 \times 2 \mathrm{~mm}$, estames ca. 51 , filetes ca. $7 \mathrm{~mm}$ compr., estigma 6-7 lobado, ca. $3 \times 2 \mathrm{~mm}$, estilete ca. $11 \times 1 \mathrm{~mm}$; frutos globosos, revestidos por aréolas cerdosas, ca. $10 \mathrm{~mm}$ compr., róseo-magenta a vermelho quando maduro, remanescentes do perianto caducos; sementes ca. $1 \mathrm{~mm}$ compr., obovóides, castanhoavermelhadas, testa verrucosa.

Material examinado: Rio Preto, 3.X.1987, fl., F.R. Salimena-Pires \& M.C. Brügger (CESJ 21615); 23.X. 1988, fl., R.C. Oliveira (CESJ 22682); 10.XI.2005, fr., 
K. Antunes et al. 195 (CESJ); 17.IV.2006, fr., N.L. Abreu et al. 70 (CESJ); 28.IV.2012, fr., D.R. Gonzaga (CESJ 59838); 29.IX.2012, fl., D.R. Gonzaga et al. 34 (CESJ); 27.XII.2012, fr., D.R.Gonzaga \& M.R.Magalhães-Silva 128 (CESJ).

Rhipsalis pilocarpa é endêmica do Brasil e ocorre nos estados da Região Sudeste e Paraná (Zappi et al. 2013). Diferencia-se das demais espécies do gênero na Serra Negra pela presença de cerdas ao longo dos ramos e nos frutos. Observada comumente com hábito epifítico, embora indivíduos rupícolas tenham sido também observados na Serra Negra. Encontrado apenas na floresta de grota do Cânion da Gruta do Funil (a ca. 900 m.s.m.), com grande número de indivíduos observados. É uma espécie considerada "Vulnerável" (Silva et al. 2011) segundo critérios da IUCN e "Em Perigo" segundo a Lista de Espécies Ameaçadas da Flora de Minas Gerais (Biodiversitas 2007).

\section{Agradecimentos}

Os autores agradecem ao Centro de Ensino Superior de Juiz de Fora, a Universidade Federal de Juiz de Fora pelo apoio logístico e à Dra. Fátima Salimena, curadora do herbário CESJ.

\section{Referências}

Abreu, N.L.; Menini Neto, L. \& Konno, T.U.P. 2011. Orchidaceae das Serras Negra e do Funil, e similaridade florística entre formações campestres e florestais do Brasil. Acta Botanica Brasilica 25: 58-70.

Arbo-Gallas, D. \& Verçoza, F.C. 2012. A família Cactaceae na Restinga de Grumari, Rio de Janeiro, RJ, Brasil. Revista Eletrônica de Biologia 5: 129-143.

Biodiversitas. 2007. Listas das espécies da flora ameaçadas de extinção do estado de Minas Gerais. Disponível em < http://www.biodiversitas.org.br/listas-mg/ lista_floramg.asp>. Acesso em 25 Jul 2012.

Blaser, J.; Salimena, F.R.G. \& Chautems, A. 2012. Gesneriaceae na Serra Negra, Minas Gerais, Brasil. Rodriguésia 63: 705-714.

Calvente, A.M.; Freitas, M.F. \& Andreata, R.H.P. 2005. Listagem, distribuição geográfica e conservação das espécies de Cactaceae no estado do Rio de Janeiro. Rodriguésia 56: 141-162.

Calvente, A. 2010. Filogenia molecular, evolução e sistemática de Rhipsalis (Cactaceae). Tese de Doutorado. Universidade de São Paulo, São Paulo. 195p.

Drummond, G.M.; Martins, C.S.; Machado, A.B.M.; Sebaio, F.A. \& Antonini, Y. (eds.). 2005. Biodiversidade em Minas Gerais: um atlas para sua conservação. 2a ed. Fundação Biodiversitas, Belo Horizonte. 222p.
Dutra, S.M.; Salimena, F.R.G. \& Menini Neto, L. 2012. Annonaceae na Serra Negra, Minas Gerais, Brasil. Rodriguésia 63: 785-793.

Feliciano, E.A. \& Salimena, F.R.G. 2011. Solanaceae A. Juss. na Serra Negra, Rio Preto, Minas Gerais. Rodriguésia 62: 55-76.

Fidalgo, O. \& Bononi, V.L.R. 1989. Técnicas de coleta, preservação e herborização de material botânico. Instituto de Botânica, São Paulo. 61p.

Freitas, M.F. 1992. Cactaceae da Área de Proteção Ambiental da Massambaba, Rio de Janeiro, Brasil. Rodriguésia 42/44: 67-91.

Gonzaga, D.R; Zappi, D.; Furtado, S.G. \& Menini Neto, L. 2014. Cactaceae no Parque Estadual do Ibitipoca, Minas Gerais, Brasil. Boletim de Botânica da Universidade de São Paulo 31 (no prelo).

Hunt, D.; Taylor, N. \& Charles, G. 2006. The new cactus lexicon. DH books, Milborne Port. 900p.

IUCN 2013. IUCN Red List of Threatened Species. Version 2013.1. Disponível em < www.iucnredlist. org >. Acesso em 17 Jul 2013.

Lombardi, J.A. 1991. O gênero Rhipsalis Gärtner (Cactaceae) no estado de São Paulo I. Espécies com ramos cilíndricos ou subcilíndricos. Acta Botanica Brasilica 5: 53-76.

Lombardi, J.A. 1995. O gênero Rhipsalis Gärtner (Cactaceae) no estado de São Paulo II. Espécies com ramos aplanados. Acta Botanica Brasilica 9: 151-161.

Matozinhos, C.N. \& Konno, T.U.P. 2011. Diversidade taxonômica de Apocynaceae na Serra Negra, MG, Brasil. Hoehnea 38: 569-595.

Mendes, Z.R. \& Sebastiani, R. 2012. Cactaceae from Reserva Biológica do Alto da Serra Paranapiacaba, Santo André, São Paulo State, Brazil. Hoehnea 39: 409-419.

Menini Neto, L.; Matozinhos, C.N.; Abreu, N.L.; Valente, A.S.M.; Antunes, K.; Souza, F.S.; Viana, P.L. \& Salimena, F.R.G. 2009. Flora vascular não-arbórea de uma floresta de grota na Serra da Mantiqueira, Zona da Mata de Minas Gerais, Brasil. Biota Neotropica 9: 149-161.

Mezzonato-Pires, A.C.; Salimena, F.R.G. \& Bernacci, L.C. 2013. Passifloraceae Juss. ex Russel na Serra Negra, Minas Gerais, Brasil. Rodriguésia 64: 123-136.

Rizzini, C.M.; Ferreira, C.; Occhioni, E.M.L. \& Agarez, F.V. 1990. Considerações sobre ocorrência de Cactaceae na APA de Maricá, Rio de Janeiro, Brasil. Acta Botanica Brasilica 4: 171-182.

Salimena, F.R.G.; Matozinhos, C.N.; Abreu, N.L.; Ribeiro, J.H.C.; Souza, F.S. \& Menini Neto, L. 2013. Flora fanerogâmica da Serra Negra, Minas Gerais, Brasil. Rodriguésia 64: 311-320. 
Silva, S.R.; Zappi, D.C.; Taylor, N. \& Machado, M. (orgs.). 2011. Plano de ação nacional para a conservação das cactáceas. Série Espécies Ameaçadas n ${ }^{\circ} 4$. Instituto Chico Mendes, Brasília. 112p.

Souza, F.S.; Salino, A.; Viana, P.L. \& Salimena, F.R.G. 2012. Pteridófitas da Serra Negra, Minas Gerais. Acta Botanica Brasilica 26: 378-390.

Souza, V.C. \& Lorenzi, H. 2012. Botânica sistemática: guia ilustrado para identificação das famílias de Angiospermas da flora brasileira, baseado na APG III. $3^{\text {a }}$ ed. Instituto Plantarum, Nova Odessa. 768p.

Taylor, N.P. \& Zappi, D.C. 1991. Cactaceae do vale do rio Jequitinhonha (Minas Gerais). Acta Botanica Brasilica 5: 63-69.

Taylor, N.P. \& Zappi, D.C. 1997. Nomenclatural adjustments and novelties in Brazilian Cactaceae. Cact. Consensus Initiatives 3: 7-8.

Taylor, N.P. \& Zappi, D.C. 2004. Cacti of Eastern Brazil. Royal Botanic Gardens, Kew. 499p.

Thiers, B. [continuously updated]. Index Herbariorum: A global directory of public herbaria and associated staff. New York Botanical Garden's Virtual Herbarium. Disponível em $<$ http:// sweetgum.nybg.org/ih/> Acesso em 1 Out 2012.
Valente, A.S.M.; Garcia, P.O.; Salimena, F.R.G. \& Oliveira-Filho, A.T. 2011. Composição, estrutura e similaridade florística da Floresta Atlântica, na Serra Negra, Rio Preto - MG. Rodriguésia 62: 321-340.

Zappi, D.C. 1989. A família Cactaceae nos campos rupestres da Cadeia do Espinhaço Minas Gerais, Brasil. Dissertação de Mestrado. Universidade de São Paulo, São Paulo. 272p.

Zappi, D.C. 1990. Flora da Serra do Cipó, Minas Gerais: Cactaceae (1). Boletim de Botânica da Universidade de São Paulo 12: 43-59.

Zappi, D.C. \& N.P. Taylor. 2003. Flora de Grão Mogol, Minas Gerais: Cactaceae. Boletim de Botânica da Universidade de São Paulo 21: 147-154.

Zappi, D.C.; Aona, L.Y.S. \& Taylor, N. 2007. Cactaceae. In: Wanderley, M.G.L.; Shepherd, G.J.; Melhem, T.S. \& Giulietti, A.M. (eds.). Flora fanerogâmica do estado de São Paulo. Vol. 5. Instituto de Botânica, São Paulo. Pp. 163-193.

Zappi, D.C.; Taylor, N.P. \& Machado, M. 2013. Cactaceae. In: Lista de espécies da flora do Brasil. Jardim Botânico do Rio de Janeiro. Disponível em $<$ http://floradobrasil.jbrj.gov.br/2012/FB000070>. Acesso em 3 Mai 2013. 